\title{
Insights into the production and characterization of electrospun fibers from regenerated silk fibroin
}

\author{
Concepción Solanas ， Sara Herrero ，Aravind Dasari , Gustavo R. Plaza ， Javier Llorca ， \\ José Pérez-Rigueiro , Manuel Elices , Gustavo V. Guinea
}

\begin{abstract}
A B S T R A C T
Regenerated silk fibroin solutions from Bombyx mori were tested for electrospinning. Simple and reproducible tensile tests were performed on threads of aligned fibers to obtain information about their mechanical performance at the fiber level. The binary solvent formic acid/chloroform $(10: 1, \mathrm{v} / \mathrm{v})$ rendered unbeaded thinner fibers with increased extensibility before failure when compared with pure formic acid. A remarkable improvement in strength was induced by immersing length-restricted fibers into ethanol for $5 \mathrm{~min}$. Conformational changes of the protein chains were studied by solid-state NMR.
\end{abstract}

\section{Introduction}

Regenerated silk fibroin (SF) from Bombyx mori has been proven to be fully biocompatible [1] and can be processed in different formats (films, 3D-sponges, hydrogels, nanofibers, etc.), which makes it possible to tune their degradability rate $[2,3]$. On the other hand, the morphology of a biomaterial greatly influences its bio-application, and porous architectures composed of nanofibers that could mimic the native nanofibrous extracellular matrix (ECM) [4,5] are especially promising for tissue regeneration [6-8].

Electrospinning is an attractive method of producing nanoscale fibers from both natural [9-13] and synthetic polymers [14-18] with diameters ranging from tens of nanometers to few micrometers. Electrospinning of silk was first reported by Zarkoob et al., who used hexafluoro-2-propanol (HFIP) to dissolve native silk from both Nephila clavipes and B. mori [19]. Solvent type greatly influences the electrospinning behavior of the regenerated fibroin solution, but other experimental parameters such as molecular weight distribution and chemistry of the constituent proteins, concentration and $\mathrm{pH}$ of the solution, voltage, spinning distance, relative humidity and temperature also have their effect on the spinning process and thus on the properties of the obtained fibers [10,20-44].

Different techniques have been used to characterize the electrospun materials in terms of fiber morphology, size and porosity, but also structural features such as 
crystallinity and molecular conformation have been studied $[21-34,36]$. However, the mechanical properties of the electrospun fibroin materials produced have been analyzed only in some cases [21-24,30-33]. In addition, due to experimental difficulties and limitations, the tensile tests have been performed mostly on electrospun fiber mats rather than on single fibers or aligned yarns of fibers [27]. An appropriate methodology to obtain and analyze electrospun aligned fibers is needed, as they offer the potential to mimic oriented tissue architecture as the one found in ligament or muscle tissue $[13,37,38]$.

In this work we addressed both the morphological and mechanical characterization of electrospun threads of aligned fibers, which were further correlated with our NMR structural studies. For this purpose, we used regenerated silk fibroin (SF) and explored both aqueous and nonaqueous solvents to prepare the spinning dopes.

In addition, we wanted to analyze the influence that the introduction of subtle changes in the electrospinning solution might have on the properties of both aligned yarns and non-woven fiber mats. We particularly focused on solvent composition and compared pure formic acid (FA) with a mixture FA/chloroform $(10: 1 \mathrm{v} / \mathrm{v})$. Finally, the effect of a very short ethanol immersion as post-spinning treatment was also studied at both the macroscopic and molecular levels.

\section{Experimental section}

\subsection{Preparation of spinning dopes}

B. mori silkworm silk cocoons were kindly supplied by Dr. Silvia Cappellozza from Consiglio per la Ricerca e la Sperimentazione in Agricoltura, Bologna (Italy). Cocoons were cut into small pieces and impurities were discarded. Sericin was removed by two repeated boiling treatments in aqueous $0.5 \%(\mathrm{w} / \mathrm{v}) \mathrm{Na}_{2} \mathrm{CO}_{3}$ for $30 \mathrm{~min}$, each followed by thorough rinse with deionized water at $80^{\circ} \mathrm{C}$ for $10 \mathrm{~min}$. Degummed silk was then allowed to dry at room temperature for 24-48 $\mathrm{h}$ and dissolved in aqueous 9.4 M LiBr. SF solution was next dialyzed against aqueous $20 \%(\mathrm{w} / \mathrm{v})$ polyethylene glycol (PEG) for 3 days (Fisher scientific, Slide-A-Lyzer Dialysis Cassette; MWCO 3500), rendering a $\sim 20 \mathrm{wt} \%$ fibroin concentration. SF aqueous solutions ranging 5-30 wt\% were used for electrospinning. In some cases, $5-10$ wt\% of FA was added to the dope solution prior spinning. Alternative non-aqueous spinning dopes were prepared from lyophilized powder after freeze-drying of freshly dialyzed SF solution. Solid SF was dissolved in pure FA or in a mixture FA/chloroform $(10: 1 \mathrm{v} / \mathrm{v})$ at room temperature, to obtain 18 and $17 \mathrm{wt} \%$ silk solutions, respectively. Continuous stirring was applied for $24 \mathrm{~h}$ to ensure complete dissolution.

\subsection{Electrospinning}

Each fibroin solution was fed into a 3-mL polypropylene syringe fitted to a 22 -gauge stainless-steel needle $(0.7 \mathrm{~mm}$ I.D.) and mounted on an electrically controlled pump (KD Scientific). The steel capillary tube was maintained at high electric potential using a high voltage power supply (NANON-01A, Mechanics Electronic Computer Corporation Ltd., Japan). Non-woven mats were deposited on an aluminum foil plate used as a stationary collector, while a rotating disk ( $\varnothing 25 \mathrm{~cm} ; 1500 \mathrm{rpm}$ ) was employed to obtain aligned yarns of fibers. The distance between the spinneret and the collector was $10-20 \mathrm{~cm}$, the flow rate of the feedstock was $0.2-1.0 \mathrm{~mL} / \mathrm{h}$ and the applied voltage was 5$20 \mathrm{kV}$.

Non-woven mats and aligned fibers obtained from $18 \mathrm{wt} \% \mathrm{SF}$ solutions in pure FA and spun at voltage of $15 \mathrm{kV}$, distance of $15 \mathrm{~cm}$, and $1 \mathrm{~mL} / \mathrm{min}$ flow rate are termed S1. Analogous samples electrospun at identical experimental conditions (i.e. $15 \mathrm{kV}, 15 \mathrm{~cm}, 1 \mathrm{~mL} / \mathrm{min}$ ) from $17 \mathrm{wt} \%$ SF dopes in FA/chloroform 10:1 (v/v) will hereinafter be referred to as $\mathbf{S 2}$.

In some cases, as-spun non-woven mats were further immersed in pure ethanol for $5 \mathrm{~min}$ and let them dry overnight. Aligned threads of fibers were also subjected to this post-spinning step with or without length restriction (see Section 2.3.4). Samples obtained from S1 and S2 after the alcohol post-treatment will be referred to as S1-E and S2-E, respectively.

\subsection{Characterization of electrospun samples}

\subsubsection{Morphological characterization}

The morphology of nanofibrous mats was analyzed by Scanning Electron Microscopy (JEOL JSM 6300) with an automated pressure regulation system. A low accelerating voltage ( $10 \mathrm{kV})$ was used for imaging after coating samples with gold. Fiber diameters were determined by measuring $\sim 100-200$ fibers randomly selected from each electrospun material using ImageJ software [45].

\subsubsection{Wide angle X-ray diffraction (WAXD) analysis}

WAXD patterns were recorded by a Philips X'Pert-MPD (EQ 31-02) diffractometer operating at $45 \mathrm{kV}$ and $40 \mathrm{~mA}$ with a $\mathrm{C} u \mathrm{~K}_{\alpha}$ radiation $(\lambda=1.54 \AA)$. All the experiments were conducted at room temperature in the reflection mode. A continuous scan rate of $0.040^{\circ} / \mathrm{min}$ was applied within the scanning region of $2 \theta=5^{\circ}-35^{\circ}$.

\subsubsection{Solid-state NMR structural study}

${ }^{13} \mathrm{C}$ cross-polarization magic-angle spinning (CP-MAS) NMR experiments were carried out on a Bruker Advanced $400 \mathrm{MHz}$ Wide Bore (9.39 T) spectrometer operating at $100.6 \mathrm{MHz}$ for ${ }^{13} \mathrm{C}$ resonance. Samples were spun at $12 \mathrm{kHz}$ (MAS) in a $4 \mathrm{~mm}$-diameter $\mathrm{ZrO}_{2}$ rotor at room temperature. Spectra were acquired with a ramp $\mathrm{CP}$ contact time of $2 \mathrm{~ms}, 1 \mathrm{H} 90^{\circ}$ pulse width of $2.5 \mu \mathrm{s}$, recycle delay of $5 \mathrm{~s}$ and acquisition time of $50 \mathrm{~ms}$. A total of 5000 12000 scans were collected over a spectral width of $28.3 \mathrm{kHz}$. TPPM15 $1 \mathrm{H}$ decoupling with field strength of $62 \mathrm{kHz}$ was applied during signal acquisition. Chemical shifts were reported relative to external adamantine (29.5 ppm). For each sample, NMR Ala C $\beta$ peak was deconvoluted into Gaussian functions using Fityk software in order to analyze quantitatively each secondary structure. 
It was previously shown that the $\mathrm{CP}$ efficiencies of SF are similar for the different conformational environments [46].

\subsubsection{Tensile tests of electrospun threads}

Yarns of aligned fibers were extracted from the edge of the rotating disk collector. One thread was made from six yarns obtained from the same batch (Fig. 1) and its length was measured with a ruler. Each thread of aligned fibers was then weighed four times on an analytical balance (OHaus DV215CD) and its weight averaged. The linear density $(\mu)$ of every thread was calculated and expressed in textile units $(1$ denier $=1 \mathrm{~g} / 9000 \mathrm{~m})$.

Each thread of fibers was mounted and fixed by tape and glue onto a series of plastic frames (Fig. 2) [47]. These strips were next cut to obtain $10-12$ samples $(10 \mathrm{~mm}$ in length) from the same thread (i.e. from the same batch). 'Control' (S1, S2) and 'ethanol-treated' (S1-E, S2-E) specimens were generated from adjacent samples.

Uniaxial tensile tests were then performed on an Instron 4411 (Canton, MA, USA) operated at $0.2 \mathrm{~mm} / \mathrm{min}$, as described elsewhere [47]. All tests were carried out at $22{ }^{\circ} \mathrm{C}$ and $40 \%$ relative humidity. The linear density $(\mu)$ obtained for each thread was used to calculate the 'massstress' $(s)$ values, which were represented versus nominal 'strain' (e):

$s=\frac{F}{\mu} ; e=\frac{L-L_{0}}{L_{0}}=\frac{L}{L_{0}}-1$

where $F$ is the force, and $L$ and $L_{0}$ the actual and initial lengths of the sample, respectively.

In order to compare with the literature, true stress $(\sigma)$ and true strain $(\varepsilon)$ values were also calculated, assuming a volumetric density $(\rho)$ equal to that of natural silk fibers $\left(\sim 1.25 \mathrm{~g} / \mathrm{cm}^{3}\right)$ and under the hypothesis of volume constancy during deformation [48]:

$$
\begin{aligned}
& \sigma=\frac{F}{A}=\frac{F}{A} \cdot \frac{A \cdot L}{A_{0} \cdot L_{0}} \cdot \frac{\rho}{\rho}=S \cdot \frac{L}{L_{0}} \cdot \rho \\
& \varepsilon=\ln \frac{L}{L_{0}}=\ln (1+e)
\end{aligned}
$$

where $A$ and $A_{0}$ are the instantaneous and initial crosssectional areas, respectively, and $\mu=\rho A_{0}$.

Values of ultimate stress $\left(s_{\mathrm{u}}, \sigma_{\mathrm{u}}\right)$, strain at breaking ( $e_{\mathrm{u}}$, $\varepsilon_{\mathrm{u}}$ ) and initial elastic modulus $(E)$ were considered for analysis and comparison between samples.

\subsection{Statistical analyses}

All reported values were averaged and expressed as mean \pm standard deviation (SD). Statistical differences were determined by Student $t$ test and considered significant at $p<0.05$.

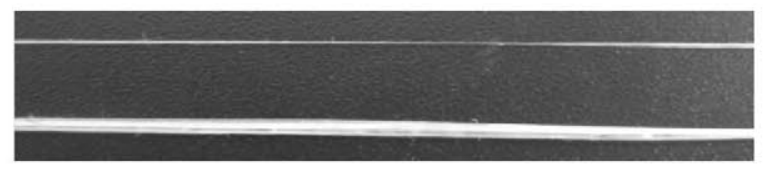

Fig. 1. Comparison between a yarn of fibers (top) and a thread made from six yarns (bottom).

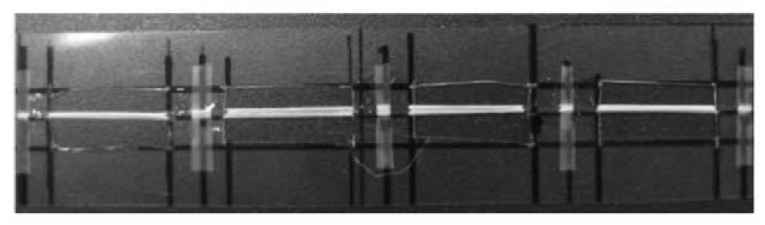

Fig. 2. Thread of aligned fibers mounted and fixed onto a series of frames.

\section{Results and discussion}

\subsection{Electrospinning of aqueous solutions}

The electrospinning process is known to be influenced by solution parameters (composition, viscosity, conductivity, surface tension, etc.), processing parameters (electric field strength, flow rate, distance to the collector, etc.), as well as ambient parameters (temperature and humidity) $[10,16,20,22-24,27-33,35,39-44,49,50]$. In this work, most of these experimental variables have been controlled and the influence of some of them on the electrospinning process has been examined. Some authors have reported lack of reproducibility arising from the source material as well as from the regeneration, spinning and/or post-spinning procedures $[21,22,27,33]$, hence the importance of working on well-identified batches.

In our study, freshly dialyzed SF aqueous dopes were first analyzed for electrospinning. At silk concentrations below $10 \%(w / w)$, the jet was discontinuous and a phenomenon similar to electrospraying was observed. This event has been reported to occur at low polymer concentrations and/or with low-weight molecules [10,24,44,51]. Fibers could be thus obtained at higher SF concentrations (up to $20 \mathrm{wt} \%$ ), although they greatly varied in size due to the instability of the jet formed (data not shown). These experimental difficulties arising from the use of aqueousbased dopes might be due to the particular combination of high surface tension, low net charge density and low vapor pressure of water [44]. Previous studies evidenced the need to use polymer blends (e.g. with PEO) [27,36], rather high SF concentrations (28-30 wt\%) $[24,35]$ and/or addition of salts to the dope solution [23] in order to stabilize the aqueous electrospinning process. In our work, the jet became very stable when $5-10 \mathrm{wt} \%$ FA was added to aqueous solutions of $10-20 \mathrm{wt} \% \mathrm{SF}$ and when they were electrospun at voltages below $15 \mathrm{kV}$. Although uniformsized fibers were obtained in this case, they included many beads and defects (data not shown). For all these reasons, we explored organic liquids as solvent systems for SF, as described below.

\subsection{Electrospinning of non-aqueous solutions}

FA is a moderate strong acid $\left(K_{\mathrm{a}}=1.8 \times 10^{-4}\right)$, but it is widely used for electrospinning of regenerated SF $[10,20,25,26,28,30-32,34]$, as silk molecules are relatively stable in this solvent without any severe degradation in the course of the experiments [26,52]. We prepared SF solutions of $18 \%(\mathrm{w} / \mathrm{w})$ concentration by dissolving the 
lyophilized powder in pure FA and tested them at different values of the experimental electrospinning parameters. When a feeding rate of $1 \mathrm{~mL} / \mathrm{min}$ was applied, the process became stable at voltages above $11 \mathrm{kV}$. Defect-free and uniform fibers were obtained at $18 \mathrm{kV}$ combined with a distance of $15 \mathrm{~cm}$ between the needle tip and the static collector plate (S1, Fig. 3).

A binary solvent (FA/chloroform 10:1 (v/v)) was next used to prepare $17 \mathrm{wt} \% \mathrm{SF}$ dopes, which were electrospun at the same experimental conditions as for $\mathbf{S 1}$ (i.e. $15 \mathrm{kV}$, $15 \mathrm{~cm}, 1 \mathrm{~mL} / \mathrm{min}$ ). Uniform fibers were also obtained from this approach (S2, Fig. 3). Interestingly, although FA and chloroform greatly differ in their values of dielectric constant (58 vs 4.8 , respectively), viscosity ( 1.5 vs $0.58 \mathrm{cP}$ ) and vapor pressure ( 5.4 vs $21.1 \mathrm{kPa}$ ), stable electrospinning processes were obtained in both cases by applying identical spinning conditions. These solvents, however, exhibit close values of surface tension ( 37.7 vs $26.7 \mathrm{mN} / \mathrm{m}$ ), hence both SF dopes (i.e. FA and FA/chloroform) show similar electrospinnable behavior.

To our knowledge, this binary solvent (FA/chloroform) was used here for the first time to electrospin regenerated SF. We wanted to analyze the effect of chloroform on the spinnable behavior of the dope when mixed with FA, in order to compare it with pure FA. Chen et al. made use of the binary solvent system trifluoroacetone/dichloromethane (7:3, wt. ratio) to electrospin SF/chitosan mixtures [25]. However, they applied the same binary solvent for all the polymer blends analyzed. Thus, from their study, it is not possible to know the influence of the chlorinated solvent in the electrospinning process.

\subsection{Fiber size}

The fiber diameters of non-woven mats S1 and S2 were analyzed from the SEM images and their size distribution depicted in Fig. 4. Average diameters of $280 \pm 50 \mathrm{~nm}$ and
$150 \pm 70 \mathrm{~nm}$ were obtained for SF/FA (S1) and SF/FA/chloroform (S2) mixtures, respectively.

It is well understood that lower polymer concentrations lead to smaller sized fibers $[10,16,17,20,23,24,30,39$, $42,44,53]$. However, the slight variation in SF concentration from S1 to S2 (18 vs $17 \mathrm{wt} \%$, respectively) could not alone account for the significant differences observed in the fiber diameters. In fact, the effect of the binary system FA/chloroform [54] might explain the S2 thinner fibers, as chloroform evaporates faster than FA $[16,42,44,55]$. In addition, the particular properties (vapor pressure, viscosity, conductivity, etc.) of the ternary mixture (SF/ $\mathrm{FA}$ /chloroform) could lead to higher shear forces during fiber formation, which would in turn allow higher molecular alignment resulting in smaller diameters in the obtained fibers.

From Fig. 4, it could be concluded that the presence of chloroform (S2) not only led to smaller-size fibers but it also resulted in a better (i.e. narrower) diameter distribution than in S1. However, the standard deviation of the S2 non-woven mat $(150 \pm 70 \mathrm{~nm})$ is actually higher than that of $\mathbf{S 1}(280 \pm 50 \mathrm{~nm})$, as a consequence of the presence of a limited number of larger fibers (200-600 nm) in the S2 sample. We hypothesize that a narrow diameter range could in fact be obtained from FA/chloroform solvent by better control of the electrospinning process. Further work is required so substantiate this idea, but good results are envisaged.

After treatment with ethanol, the morphology of the fibers changed from the circular fiber cross-section of as-spun mats (S1 and S2, Fig. 2) to a ribbon-like shape (S1-E and S2-E, Fig. 2). This effect has been observed previously in SEM micrographs after immersion in dehydrating agents $[22,23,28]$, In addition, as expected, ethanol-treated fibers appear to merge together, causing a significant reduction in the porosity of the electrospun mat (Fig. 2) $[22,23,28,29,36]$.
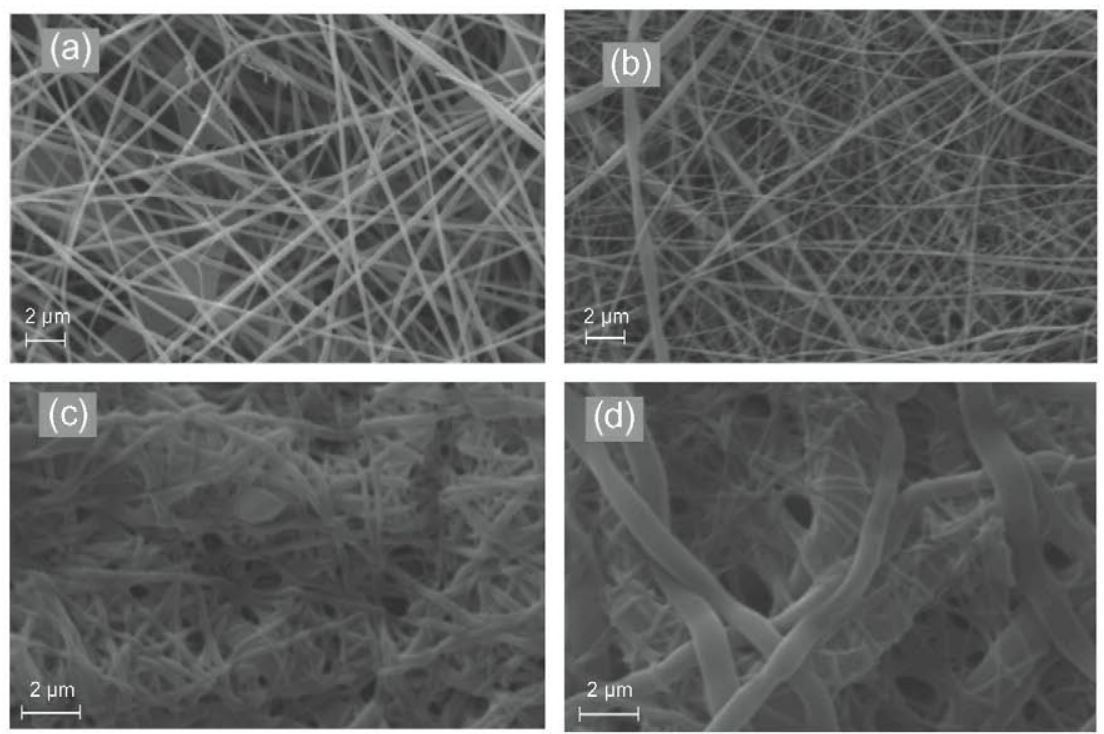

Fig. 3. SEM micrographs of as-spun (S1 (a) and S2 (b)) and ethanol-treated (S1-E (c) and S2-E (d)) mats. 

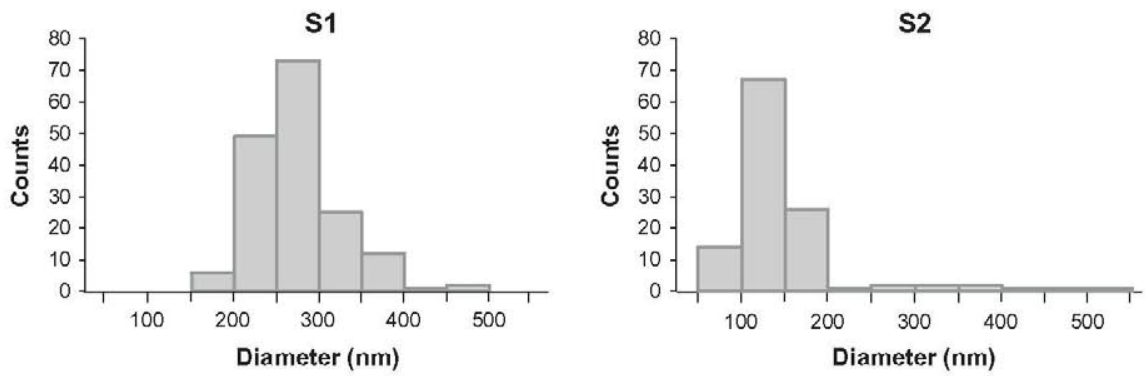

Fig. 4. Diameter distributions of non-woven mats obtained from pure FA (S1, $18 \mathrm{wt} \%, N=168)$ and $\mathrm{FA} / \mathrm{chloroform}(\mathrm{S} 2,17 \mathrm{wt} \%, \mathrm{~N}=116) \mathrm{SF}$ solutions. Electrospinning conditions: voltage, $18 \mathrm{kV}$; distance to the collector, $15 \mathrm{~cm}$; feeding rate, $1.0 \mathrm{~mL} / \mathrm{min}$.

\subsection{WAXD analyses}

Although X-ray diffraction is a complex technique, qualitative estimation about crystallinity can be readily obtained from the XRD patterns by comparison with appropriate models. We used degummed (D) and lyophilized (L) fibroin as a reference (Fig. 5). As previously reported for natural fibroin [56]. The $\mathbf{D}$ sample exhibited a pronounced peak at $2 \theta=20.6^{\circ}$ and other minor but well-defined reflections at $9.5^{\circ}, 24.6^{\circ}$, and $25.3^{\circ}$, indicative of a $\beta$-folded crystalline structure. Lyophilized silk obtained from aqueous solution (L) shows a single broad diffraction peak centered at $\sim 21.5^{\circ}$, characteristic of an amorphous molecular configuration in the solid state.

The XRD pattern of the as-spun S1 sample resembles that of the disordered lyophilized silk powder $(\mathbf{L})$, although the broad peak at $\sim 21.5^{\circ}$ appears more intense in S1 (Fig. 4). It has been proposed that, when compared with other solvents, FA promotes the $\beta$-sheet crystallization by reducing the hydrodynamic radius of the protein chains and increasing intramolecular hydrogen bonding between them [21,52]. However, the crystalline content observed in our S1 sample spun from pure FA is rather low (Fig. 4). Some authors also attributed structure-inducing properties to FA from their analyses by FTIR spectroscopy [31]. This technique makes it possible to study the protein structure

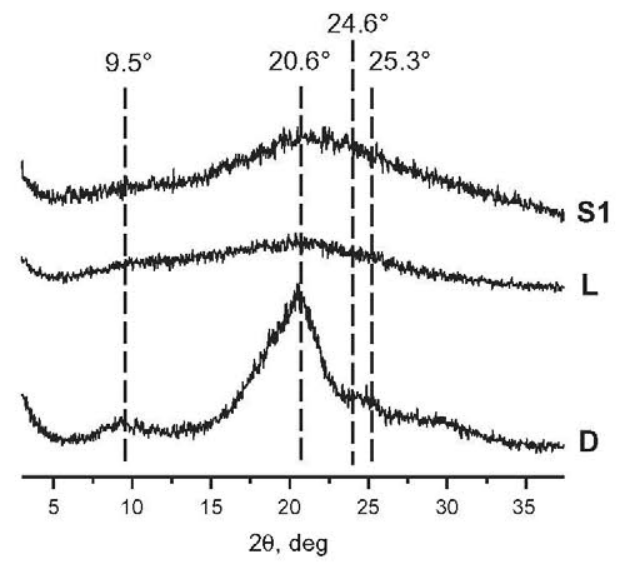

Fig. 5. XRD patterns of degummed silk (D), lyophilized silk powder (L) and electrospun non-woven mat S1. Electrospinning conditions: see Fig. 3. at the molecular level, hence assumptions about the microstructure of the fibers cannot be made. Therefore, although molecular conformation and crystallinity can be somewhat related, as crystalline materials usually result from wellordered distributions at the molecular level, complementary analyses should be carried out to address both features. In order to better examine the molecular configuration of the protein chains, we made use of $\mathrm{CP}$-MAS ${ }^{13} \mathrm{C}$ NMR.

\subsection{Study by CP-MAS ${ }^{13} \mathrm{C} N M R$}

NMR spectroscopy is a powerful technique to analyze the secondary structure of peptides and proteins, as the chemical shifts of the nuclei are greatly influenced by the polypeptide dihedral angles [57-59]. Solid-state NMR (SSNMR) can be applied under a variety of conditions not accessible to X-ray crystallography and solution NMR [60], and several protein structures have been successfully determined in the solid state by magic-angle-spinning (MAS) NMR [61-63].

Analyses by CP-MAS ${ }^{13} \mathrm{C}$ NMR have also been conducted on $B$. mori silk fibroin, as well as related model peptides [46,64-69], in order to characterize the secondary structure of SF in the worm gland before spinning (Silk I) and in the spun solid fiber (Silk II). We used degummed SF fibers (D) and lyophilized regenerated SF powder ( $\mathbf{L})$ as a reference for Silk II and Silk I structures, respectively (Fig. 6). While D actually represents the solid fibers naturally spun by $B$. mori after degumming, $\mathbf{L}$ has been obtained after freeze-drying of an aqueous solution that could mimic the conditions in the silkgland. However, it is important to note that the concentration of our regenerated silk aqueous solution ( $20 \mathrm{wt} \%)$ might differ considerably from that of the worm gland.

Silk I structure was initially proposed to be a $31_{1}$-helixlike conformation [70], but it was later identified as a repeated $\beta$-turn type II that is capable of forming intramolecular hydrogen bonds $[64,68]$. In contrast, three different molecular structures have been identified in Silk II, two antiparallel $\beta$-sheet conformations, as major components, and a distorted poly- $\beta$ II-turn structure $[64,65]$.

In our $\mathbf{D}$ and $\mathbf{L}$ spectra (Fig. 6), the resonance peaks of the main constituent amino acids of silk fibroin (i.e. Gly, Ala, Ser, Tyr) can be readily identified and their chemical shifts correlated with the molecular conformation of the 


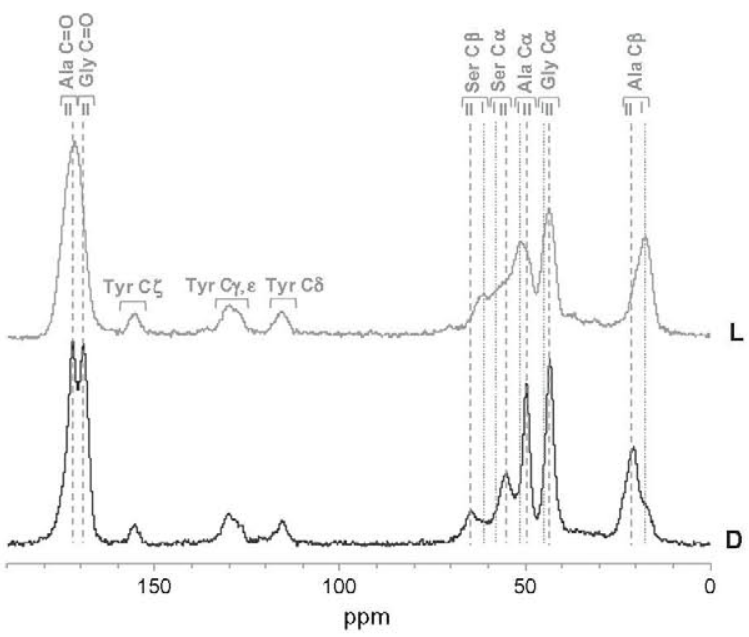

Fig. 6. ${ }^{13} \mathrm{C} \mathrm{CP} / \mathrm{MAS}$ NMR spectra of degummed silk (D) and lyophilized silk powder (L).

polypeptide $[64,65]$. As expected for a $\beta$-sheet conformation $[59,71,72]$, Ala $C \beta$ peak appears at higher frequency in degummed SF (D) than in lyophilized SF powder $(\mathbf{L})$ (20.7 ppm vs $17.3 \mathrm{ppm}$, resp.). These trends observed here are also in agreement with the proposed structures of Silk II and Silk I, that is, predominant $\beta$-sheet and repeated $\beta I$ Iturn, respectively $[64,65]$. In the same manner, Ser $C \beta$ peak appears at lower field in $\mathbf{D}(65.3 \mathrm{ppm})$ than in $\mathbf{L}(62.2 \mathrm{ppm})$, as expected from its location in a $\beta$-pleated sheet and in a poly- $\beta$ II-turn, respectively.

Conversely to the $C \beta$ signal, the Gly $C \alpha$, Ala $C \alpha$ and Ser $C \alpha$ peaks of Silk I are slightly shifted to higher frequencies when compared with those of Silk II $[64,65]$, as expected if located in a helix or in a repeated turn [73]. In our study, the differences between $\mathbf{D}$ and $\mathbf{L}$ are especially noticeable for Ala $\mathrm{C} \alpha$. The conformation-dependence of the $\mathrm{C} \alpha$ of glycine is known to be smaller than that of the $C \alpha$ and $C \beta$ atoms of Ala residues, hence the limited information obtained from the Gly C $\alpha$ chemical shift [64].

In the same manner, the carbonyl signals of the peptide bond $(C=0)$ also show different trends if the amino acid is located in a $\beta$-sheet structure or if it adopts a $\beta$-turn or helical conformation, appearing at higher and lower fields, respectively. This is the behavior exhibited by the unidentifiable $\mathrm{C}=\mathrm{O}$ peaks in the spectra of model peptides with Silk II and Silk I structures $[64,65]$. Separate carbonyl Ala and Gly signals can be also detected in our degummed sample (D) at the expected values of chemical shift for a $\beta$-sheet conformation (172.8 and 169.9 ppm, resp.). However, a single broad peak is observed in this region of the spectrum of our regenerated SF after freeze-drying $(\mathbf{L})$. This coalescence of signals typically occurs in inter-changeable and/or disordered conformations when NMR is performed in solution, and it can be associated with static disorder in solid-state NMR [62]. Therefore, fibroin molecules in lyophilized powder (L) would adopt random coil configurations or a mixture of coiled-structures, rather than the ordered poly- $\beta$-turn attributed to Silk I [64]. This lack of one single preferential motif in $\mathbf{L}$ is consistent with the flat pattern obtained from our XRD analysis (Fig. 5), and might agree with the random coil conformation proposed in previous studies [69].

It should be noted that similar NMR profiles in the Ala $C \beta$ region were interpreted differently in the literature. In fact, although the signals attributed by Dang et al. to a $\beta$ sheet conformation [69] matched those observed in Silk II by Asakura and Yao [65], the chemical shift identified by the latter author with an ordered repeated BII-turn in Silk I $[64,65]$ was associated by Dang and coworkers with a random-coiled distribution of the fibroin molecules [69]. In the study on the conformational transition from Silk I to Silk II, Zhou and colleagues describe the former state as 'helix dominant' [46]. These different interpretations of the Silk I state could arise from a mixture of coiled structures, which could in turn lack a defined long-range order $[23,24]$.

It is relatively straightforward to distinguish between the two major secondary structural elements found in proteins, $\alpha$-helices and $\beta$-sheets, as they usually adopt distinct chemical shift values [71,74]. Turn-configurations, however, generate intermediate values between those two structural motifs [75], resembling those associated with disordered or random coil distributions [72]. In addition, a loose definition of the term 'coil' as true random coils (unstructured regions) exists [72] and disordered configurations are lumped together with structures like turns and loops [76]. For this reason, more complex approaches are required $[46,75]$ to accurately identify the conformational motif of silk fibroin in the worm gland (Silk I) or in the solid state after lyophilization (L). Finally, the particular values of chemical shift could vary between experiments (i. e. experimental conditions), hence the importance of using reference samples.

After the analysis of the $1 \mathrm{D}{ }^{13} \mathrm{C}$ NMR spectra of our references, $\mathbf{D}$ and $\mathbf{L}$, we used them for comparison with the electrospun samples (Fig. 7). Spectra of both as-spun mats (S1 and S2) are similar to that of lyophilized powder (L). Only small differences are observed for Ser $C \beta$, whose resonance peak appears slightly upfielded both in S1 and S2, mid-way between $\mathbf{D}$ and $\mathbf{L}$ (Fig. 7 and Table 1). Therefore, it could be concluded that little conformational changes are induced after dissolution of $\mathbf{L}$, either in FA or FA/chloroform, and subsequent spinning into solid fibers. This minor content of $\beta$-sheets in as-spun fibers is in accordance with the small differences observed between $\mathbf{L}$ and $\mathbf{S 1}$ in their XRD patterns.

However, when $\mathbf{L}$ and $\mathbf{S 1}$ are compared with analogous samples obtained by other authors, [26] a slight increase in the amount of $\beta$-sheet was inferred from the Ala $C \beta$ peak in their as-spun nanofibers [26]. It was then proposed that the elongational forces exerted on the SF/FA solution during electrospinning could promote this conformational transition from the lyophilized powder to the electrospun fibers [26]. Similarly, Zhang et al. have also attributed intrinsic structure-inducing properties to FA as a solvent for electrospinning [31]. In our NMR study, however, we did not observe significant structural differences between samples spun from SF/FA solution (S1) and lyophilized powder (L) (Fig. 7). Moreover, the additional presence of chloroform in the dope solution (S2) does not seem to 


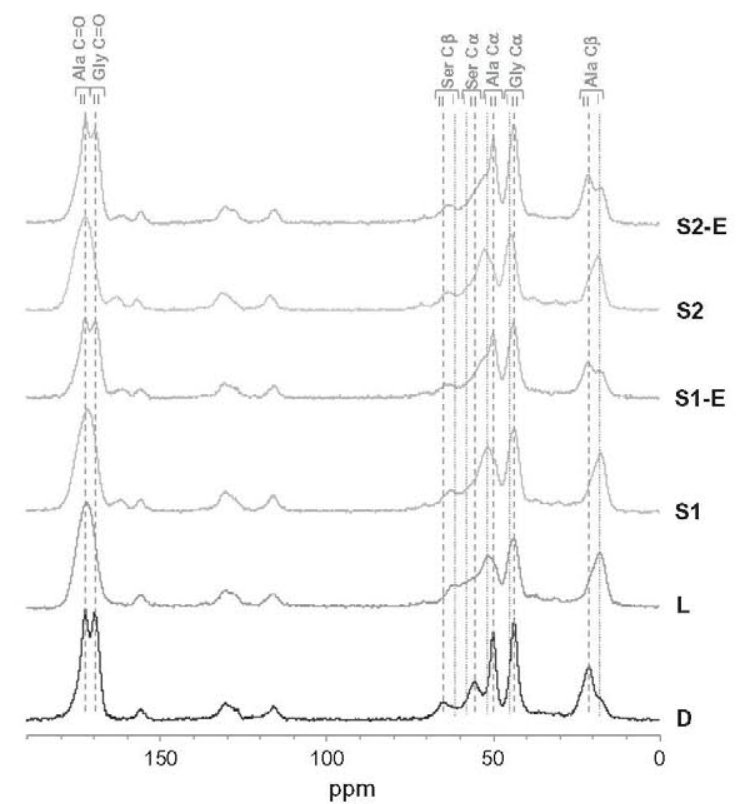

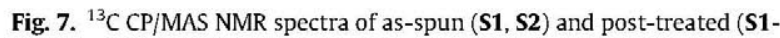
E, S2-E) non-woven mats. Spectra of the references (D, L) are shown for comparison.

influence the conformational transition either, as S1 and S2 spectra are almost identical (Fig. 7). Nonetheless, as presented above, the dope composition was observed to have an influence on the diameter of the electrospun fibers (Figs. 3 and 4).

It should be noted that FA is still present in both asspun mats (S1 and S2), as its characteristic carbonyl peak can be readily identified ( $\sim 163 \mathrm{ppm})$. Chen et al. treated their electrospun fibers with an ethanol/ammonia aqueous solution for $30 \mathrm{~min}$ to change the SF protein structure and to remove residual trifluoroacetic acid (TFA) used as electrospinning solvent [25]. Similarly, remaining hexafluroacetone in as-spun fibers was extracted after being soaked in methanol overnight to promote $\beta$-sheet formation [30]. In our study, we wanted to analyze the structural changes induced by a short ethanol treatment (i. e. $5 \mathrm{~min}$ ) on asspun fibers. Longer dehydrating times could be used to effectively eliminate non-volatile solvents (such as FA) within the fibers.

Dehydrating agents such as organic alcohols (e.g. ethanol, methanol) are known to promote structural changes by removing water molecules and favouring direct protein-protein interactions. In this study, a significant increase in the $\beta$-sheet content was obtained after immersing electrospun mats in ethanol for $5 \mathrm{~min}$, and it seemed to act fast in both cases (S1-E and S2-E, Fig. 7). After posttreatment, the Ala $C \beta$ peak at $20.7 \mathrm{ppm}$ become more intense, the Silk II component of Ala $\mathrm{C} \alpha$ gets thinner (49.6 ppm) and the carbonyl groups of Ala and Gly are almost fully resolved. Similarly, methanol has been previously reported to act rapidly and the conformational transition into $\beta$-sheet from the as-spun SF nanofibers was almost completed within $10 \mathrm{~min}$ [26].

The structural transitions observed from the lyophilized powder (L) to the as-spun (S1, S2) and post-treated (S1-E, S2-E) samples seem to occur regardless of the solvent used to prepare the silk solution prior to electrospinning. We wanted, however, to gain insight and quantify the different protein structural motifs coexisting in each sample. To this end, we further analyzed the Ala $C \beta$ signal, as it can be used as a diagnostic peak $[46,65,66,69]$. In fact, this resonance is quite sensitive to the molecular conformation and appears in a clear spectral region not overlapped with other signals. Ala $C \beta$ peak was deconvoluted into the three identified components of Silk II ( $\beta$-sheet A, $\beta$-sheet B and distorted $\beta$-turn) [65] and their ratio estimated by integration (Fig. 8 and Table 1) $[64,65,69]$. In order to find the best fit for the Ala $C \beta$ signal, the height, width and position of the three component Gaussian peaks were adjusted. Our results confirmed that both as-spun mats ( $\mathbf{S 1}$ and $\mathbf{S 2}$ ) contain similar amounts of $\beta$-sheet structures, and almost identical to the lyophilized powder $(\mathbf{L})$. Therefore, the analysis of the Ala $C \beta$ peak suggested that no conformational change is induced by electrospinning of the SF in any of the solvent systems used. It should be noted, however, that when compared with $\mathbf{L}$, a minor structural transition in asspun $\mathbf{S 1}$ and $\mathbf{S 2}$ samples could be inferred from the variation observed in the Ser $C \beta$ chemical shift (Table 1). After the short post-treatment (S1-E, S2-E), a twofold increase in the pleated-sheet content can be estimated, and ethanol might be slightly more effective on $\mathbf{S 2}$ than in $\mathbf{S 1}$ fibers to promote this conformational rearrangement (Table 1 ).

In any case, although the integrated amounts of $\beta$-sheet contents can be considered with almost absolute certainty (Table 1), the results of the random coil and turn-configurations should be taken with caution [75]. In addition, it is important to note that, after deconvolution of the Ala $C \beta$ signal, the chemical shifts of the component peaks differ slightly across samples (Table 1 ), which could reveal some

Table 1

${ }^{13} \mathrm{C}$ CP/MAS NMR chemical shifts (ppm from TMS) of the SF references (D, L) and of the as-spun (S1, S2) and post-treated (S1-E, S2-E) non-woven mats.

\begin{tabular}{|c|c|c|c|c|c|c|c|}
\hline & $\mathrm{D}$ & & $\mathrm{L}$ & S1 & S1-E & S2 & S1-E \\
\hline \multirow[t]{2}{*}{ Gly } & $\mathrm{C} \alpha$ & 43.3 & 43.3 (b) & 43.2 (b) & 43.3 & 43.5 (b) & 43.5 \\
\hline & $\mathrm{C}=\mathrm{O}$ & 169.9 & $172.4^{*}(\mathrm{~b})$ & $172.4^{*}(\mathrm{~b})$ & 170.1 & $172.3^{*}(\mathrm{~b})$ & 170.0 \\
\hline \multirow[t]{5}{*}{ Ala } & $\mathrm{C} \alpha$ & 49.6 & 51.3 (b) & 51.5 (b) & 49.6 & 51.5 (b) & 49.6 \\
\hline & $C \beta$ & $17.4(29 \%)$ & $17.4(78 \%)$ & $17.3(75 \%)$ & $17.4(49 \%)$ & $17.3(78 \%)$ & $17.4(46 \%)$ \\
\hline & & $20.4(32 \%)$ & $20.4(13 \%)$ & $20.3(14 \%)$ & 20.7 (24\%) & $20.3(12 \%)$ & $20.7(27 \%)$ \\
\hline & & $22.4(39 \%)$ & $22.4(9 \%)$ & $22.4(11 \%)$ & $22.4(27 \%)$ & $22.4(10 \%)$ & $22.4(27 \%)$ \\
\hline & $C=0$ & 172.8 & $172.4^{*}(\mathrm{~b})$ & $172.4^{*}(\mathrm{~b})$ & 172.8 & $172.3^{*}(\mathrm{~b})$ & 172.9 \\
\hline Ser & $C \beta$ & 65.3 & 62.2 & 63.2 & 64.1 & 63.3 & 64.1 \\
\hline
\end{tabular}

(b): Broad; "Ala C=O and Gly $\mathrm{C}=\mathrm{O}$ appear merged. Deconvoluted peaks are italicized. Electrospinning conditions: see Fig. 4. 

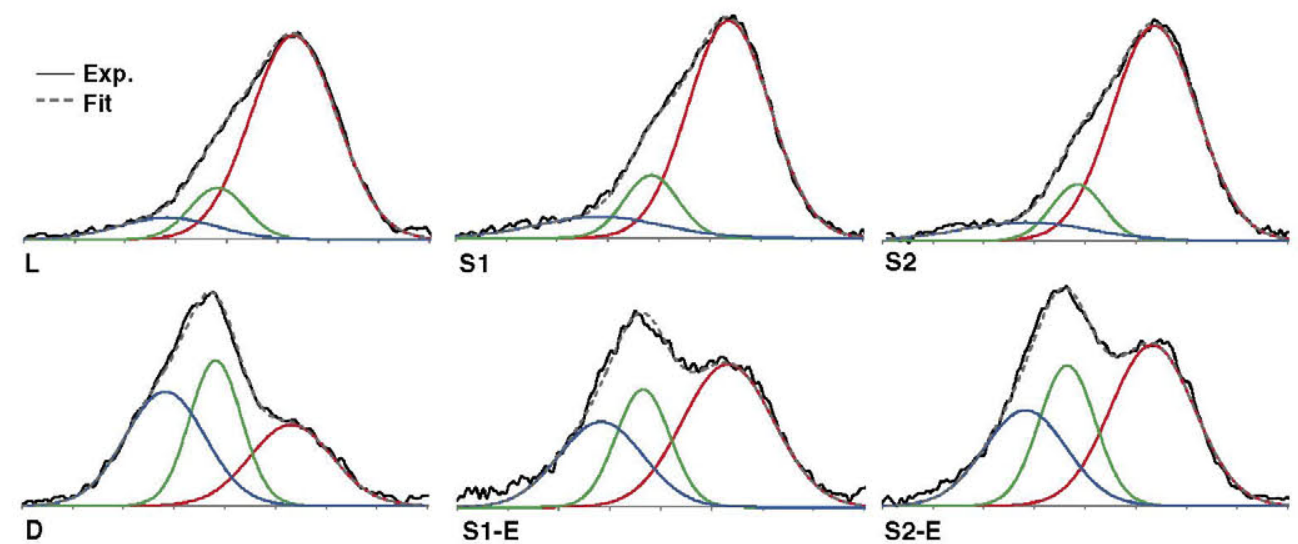

Fig. 8. Deconvolution images of the Ala $\mathrm{C} \beta$ region from the ${ }^{13} \mathrm{C} C P / M A S$ NMR spectra.

structural differences between them. The deviation from the native structure (D) is more relevant for the middle peak ( $\beta$-sheet B) and especially for S1-E and S2-E. Therefore, the $\beta$-sheet conformation obtained after ethanol treatment might differ in some way from the 'canonical' structure present in the natural SF fibers.

\subsection{Mechanical properties of aligned threads}

Most of the mechanical studies previously reported have been performed on electrospun SF mats, so they do not provide information at the fiber level [21$24,29,30,32,33]$. In addition, the experimental procedures proposed so far on single fibers are difficult and arduous to carry out [27].

Therefore, in this study we aimed to analyze the tensile behavior of electrospun silk fibroin at the fiber level by means of a simple and convenient methodology, which makes use of threads of aligned fibers. From our approach, analogous tensile curves were obtained for samples derived from the same batch (Fig. 9). Some differences have been observed, however, when we compared different batches, even when they were obtained from dopes of the same composition and spun in the same experimental conditions (Fig. 9 and Table 2). This variability between batches was also reported by other authors and it seems to be inherent to the steps involved in the experimental procedure [27].

Taking these limitations into account, similar mechanical performance is exhibited by as-spun samples obtained from dopes of different composition ( $\mathbf{S} \mathbf{1} v s \mathbf{S} \mathbf{2}$ ), particularly in terms of maximum stress. However, threads electrospun from the ternary mixture FA/chloroform/SF (S2) systematically displayed higher values of extension at breakage, and this observation is statistically significant $(p \ll 0.01$; Table 2). It has been proposed that higher shear forces during electrospinning would result in better protein alignment (regardless of their secondary structure), which would in turn produce thinner fibers $[16,17,41]$. Conversely, a higher number of chain entanglements could be found in thicker fibers, which would act as premature failure points. As a result, higher values of ultimate elongation would be expected for $\mathbf{S 2}$ than in S1, as was in fact observed (Table 2). The transmission of the applied force occurs differently in aligned protein molecules than in entangled chains. In particular, molecular entanglements
S1

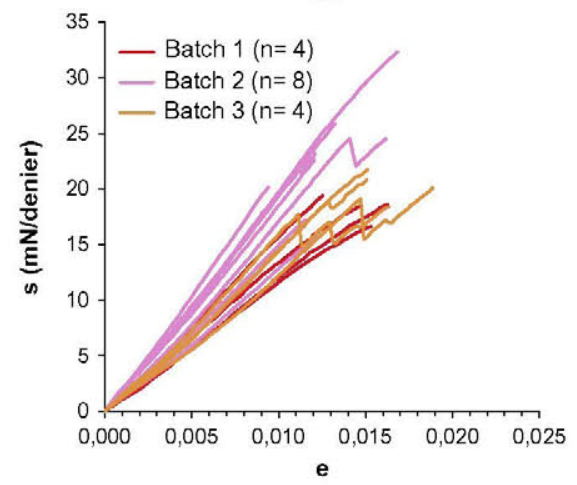

S2

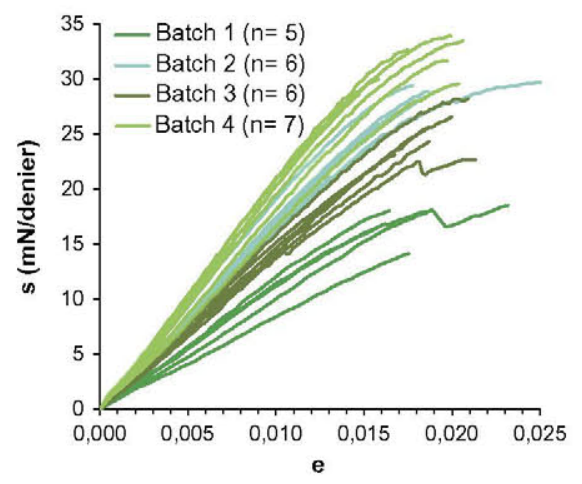

Fig. 9. Stress $v s$ Strain curves obtained for different batches of as-spun threads of aligned fibers ( $\mathbf{1} \mathbf{1}$ and $\mathbf{S 2}$ ). The number of samples tested for each batch is given in parentheses. 
Table 2

Mechanical parameters obtained for different batches of as-spun threads (S1, S2). The number of samples tested is given in parentheses. Density of natural silk fibroin fibers $\left(1.25 \mathrm{~g} / \mathrm{cm}^{3}\right)$ was assumed to calculate true stress $(\sigma)$.

\begin{tabular}{lllllll}
\hline Sample & Batch & $e_{\mathrm{u}}$ & $s_{\mathrm{u}}(\mathrm{mN} /$ denier $)$ & $\varepsilon_{\mathrm{u}}$ & $\sigma_{\mathrm{u}}(\mathrm{MPa})$ & $E(\mathrm{~N} / \mathrm{denier})$ \\
\hline S1 & $1(n=4)$ & $0.015 \pm 0.002$ & $18 \pm 1$ & $0.015 \pm 0.002$ & $208 \pm 13$ & $1.2 \pm 0.2$ \\
& $2(n=8)$ & $0.013 \pm 0.002$ & $23 \pm 5$ & $0.013 \pm 0.002$ & $259 \pm 60$ & $1.7 \pm 0.3$ \\
& $3(n=4)$ & $0.016 \pm 0.002$ & $20 \pm 1$ & $0.016 \pm 0.002$ & $231 \pm 16$ & $1.3 \pm 0.1$ \\
S2 & $1(n=5)$ & $0.018 \pm 0.003$ & $17 \pm 2$ & $0.018 \pm 0.003$ & $196 \pm 20$ & $1.0 \pm 0.1$ \\
& $2(n=6)$ & $0.020 \pm 0.004$ & $29 \pm 1$ & $0.020 \pm 0.004$ & $329 \pm 14$ & $1.6 \pm 0.1$ \\
& $3(n=6)$ & $0.019 \pm 0.002$ & $25 \pm 2$ & $0.019 \pm 0.002$ & $288 \pm 25$ & $1.4 \pm 0.1$ \\
& $4(n=7)$ & $0.018 \pm 0.002$ & $31 \pm 4$ & $0.018 \pm 0.002$ & $360 \pm 24$ & $1.9 \pm 0.2$ \\
\hline
\end{tabular}

limit the relative movement of the molecules and could contribute to a more brittle behavior.

True stress $(\sigma)$ values were estimated assuming the density of SF fibers naturally spun by B. mori $(\sim 1.25 \mathrm{~g} /$ $\mathrm{mL})$. Ultimate stress $\left(\sigma_{\mathrm{u}}\right)$ values for as-spun threads (S1 and S2) range from 196 to $360 \mathrm{MPa}$, depending on the particular batch tested (Table 2). These values are comparable with the best bio-inspired fibers [53,76-78] and remarkably close to those found in degummed natural silk fibers (300-600 MPa) [47]. Similar outstanding results were obtained here for the Young moduli $(E, G P a)$ of as-spun fibers (14-20 GPa; Table 2), which resemble those of natural silk fibroin (9-17 GPa) [47] However, it should be noted that the actual densities of the threads made from aligned fibers in our study can be significantly lower than that of natural silk, due to the lower crystallinity of the electrospun fibers and the voids between them. Therefore, both the ultimate stress $\left(\sigma_{\mathrm{u}}\right)$ and the initial elastic moduli $(E, \mathrm{GPa})$ - calculated from the assumption made aboveshould be taken with caution. On the contrary, very modest values of ultimate elongation $\left(\varepsilon_{\mathrm{u}}\right)$ are obtained here for both as-spun threads (1.3-2.0\%; Table 2$)$, when compared with those of natural degummed fibers from B. mori (2.5$10.0 \%)[47]$.

Tensile tests on post-treated fibers were further conducted to assess the mechanical effect induced by ethanol immersion. Analyses were first performed on threads mounted onto the frames after alcohol post-treatment. Large differences were observed for analogous samples from this approach, as a result of fiber shrinkage and curling during ethanol soaking (data not shown). This effect is caused by the dehydrating properties of the solvent [27] when threads are exposed unrestricted to the alcohol medium, as a result of free and uncontrollable molecular rearrangement. In addition, the protein movement would be hindered by chain entanglements and knots, causing the macroscopic fiber to bend and loop.

Ethanol treatment was then applied on fibers previously mounted onto the plastic frames. For comparison, both as-spun and post-treated samples were generated from the same thread. Highly-reproducible results were obtained from this approach and an increase in strength was achieved after ethanol immersion (S1-E and S2-E, Fig. 10). This improvement is especially remarkable after post-treatment of as-spun S2 samples (S2-E).

We suggest that the $\beta$-sheet content is increased by alcohol treatment both in restricted and unrestricted samples, as inferred from the NMR analyses on non-woven mats (Fig. 7). However, we hypothesize that length fixation prior to the ethanol immersion induces the molecular rearrangement to occur along the fiber axis, resulting in higher chain alignment and $\beta$-sheet stacking stabilized by a quite ordered hydrogen-bonding network, which might lead to a higher degree of crystallinity. On the contrary, when fibers are freely exposed to the dehydrating agent, the conformational transition to $\beta$-sheet, as well as the protein-protein interactions, would occur in a rather random manner.

Ethanol immersion seems to be more effective for S2 than for $\mathbf{S 1}$, as a notable increase in ultimate strength $\left(s_{\mathrm{u}}\right)$ was obtained after S2 post-treatment (from 17 to $35 \mathrm{mN}$ / denier), but only a minor change is observed for $\mathbf{S 1}$ (from 18 to $24 \mathrm{mN} /$ denier) (Fig.10 and Table 3). The same differences become apparent between S1 and S2 after ethanol immersion from the respective increases in the initial elastic modulus ( $E$; Table 3 ). These observations would be in accordance with our hypothesis that thicker fibers (S1) might contain a higher number of chain entanglements and knots, which would hamper the molecular movement mediated by ethanol. As a result, although the conformational transition to $\beta$-sheet could occur locally in samples of both sizes (S1 and S2), $\beta$-stacking and crystallization would take place to a greater extent in S2, hence the mechanical improvement observed in S2-E. In addition, it could be proposed that the mechanical test itself could also induce the alignment of the protein chains at the molecular level and/or the stacking or growth of the $\beta$-sheet crystallites at the microscopic level.

The estimated values (see above) of ultimate true stress $\left(\sigma_{\mathrm{u}} ; \mathrm{MPa}\right)$ and Young modulus ( $E$; GPa) obtained after ethanol immersion of both as-spun threads (S1 and S2), but especially those of S2 (266 MPa and $30 \mathrm{GPa}$ for S1-E and $404 \mathrm{MPa}$ and $32 \mathrm{GPa}$ for S2-E), compare well not only with the values reported in the literature for regenerated silk fibroin fibers $[53,76-78]$, but also with those of natural $B$. mori silk [47].

Finally, the differences observed initially between $\mathbf{S 1}$ and $\mathbf{S 2}$ in their respective strain at rupture $\left(e_{\mathrm{u}}\right)$ (Fig. 9; Table 2) were also maintained after post-treatment (Fig. 10). As macroscopic fiber elongation might be mediated by the unwinding of the protein chains located in amorphous regions, alcohol-treated non-woven mats with high crystalline contents are often brittle $[29,36]$. This fact would be in accordance with the premature failure observed in post-treated threads (S1-E and S2-E) when compared with as-spun (S1 and S2) samples ( $\boldsymbol{e}_{\mathbf{u}}$; Table 3 ). However, ethanol seemed to affect S1 and S2 differently, 

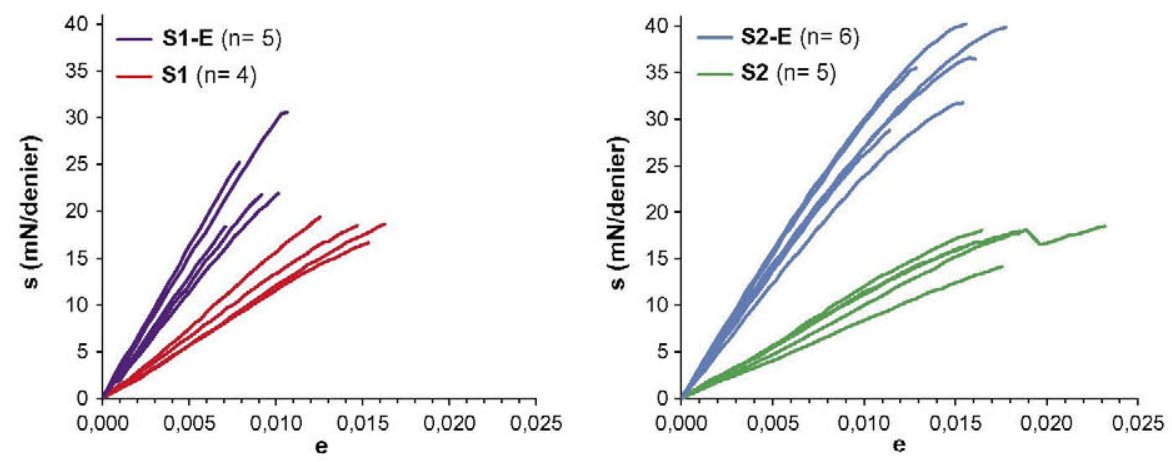

Fig. 10. Stress vs Strain curves of as-spun (S1 and S2) and post-treated (S1-E and S2-E) samples obtained from the same thread of aligned fibers (S1 or S2). The number of samples tested is given in parentheses.

Table 3

Mechanical parameters of as-spun (S1, S2) and post-treated (S1-E, S2-E) aligned fibers obtained from the same thread. The number of samples tested is given in parentheses. Density of natural silk fibroin fibers $\left(1.25 \mathrm{~g} / \mathrm{cm}^{3}\right)$ was assumed to calculate true stress $(\sigma)$.

\begin{tabular}{lllllll}
\hline Sample & $e_{\mathrm{u}}$ & $s_{\mathrm{u}}(\mathrm{mN} /$ denier $)$ & $\varepsilon_{\mathrm{u}}$ & $\sigma_{\mathrm{u}}(\mathrm{MPa})$ & $E(\mathrm{~N} /$ denier $)$ & $E(\mathrm{GPa})$ \\
\hline S1 $(n=4)$ & $0.015 \pm 0.002$ & $18 \pm 1$ & $0.015 \pm 0.002$ & $208 \pm 13$ & $1.2 \pm 0.2$ & $14 \pm 2$ \\
S1-E $(n=5)$ & $0.009 \pm 0.002$ & $24 \pm 5$ & $0.009 \pm 0.002$ & $266 \pm 50$ & $2.7 \pm 0.4$ & $30 \pm 5$ \\
S2 $(n=5)$ & $0.018 \pm 0.003$ & $17 \pm 2$ & $0.018 \pm 0.003$ & $196 \pm 20$ & $1.0 \pm 0.1$ & $12 \pm 2$ \\
S2-E $(n=6)$ & $0.015 \pm 0.002$ & $35 \pm 5$ & $0.015 \pm 0.002$ & $404 \pm 52$ & $2.9 \pm 0.3$ & $32 \pm 3$ \\
\hline
\end{tabular}

as the reduction observed in the maximum extensibilities after treatment is higher and lower, respectively (Table 3). It could be proposed that the protein loops located in the amorphous regions of S2-E would unroll during the mechanical test, thus enabling fiber elongation. On the contrary, molecular movement in the amorphous regions of S1-E might be restricted by the 'irreversible' entanglements and knots, which would result in premature mechanical failure.

As a result, although the post-spinning treatment notably improved the mechanical performance of our fibers in terms of strength $\left(\sigma_{\mathbf{u}}\right.$; Table 3$)$, the limited values of 'true strain' $\left(\varepsilon_{u}\right.$; Table 3 ) obtained for as-spun fibers (S1-E 1.5\%; S2-E $1.8 \%$ ) are further compromised after ethanol immersion (S1-E $0.9 \%$; S2-E 1.5\%), and compare poorly with those of degummed silk fibers [47].

\section{Conclusion}

In this study, several influential parameters on the electrospinning process have been examined and their values optimized to obtain uniform and unbeaded fibers from regenerated SF solutions. Morphological characterization of non-woven mats revealed that the binary solvent FA/ chloroform $(10: 1, \mathrm{v} / \mathrm{v})$ would hold great potential to produce thin fibers with narrow size distributions. A detailed study by ${ }^{13} \mathrm{C} \mathrm{CP} /$ MAS NMR spectrometry for both as-spun and ethanol-treated samples confirmed that a fast conformational transition of fibroin molecules occurred during post-treatment. Additionally, we used a simple and reproducible methodology to assess the mechanical performance of electrospun threads made from aligned fibers, which will be useful for engineering of SF electrospun scaffolds designed for structurally aligned tissues. In our study, increased values of extensibility before failure were obtained by using FA/chloroform $(10: 1, v / v)$ as electrospinning solvent when compared to pure FA. A remarkable improvement in strength has been attained after ethanol treatment of length-restricted fibers.

\section{Conflict of interest}

The authors declare no competing financial interest.

\section{Acknowledgments}

This work was funded by Ministerio de Economía y Competitividad (Spain) through the projects MAT_2012_38412_C02_01 and MAT_2012_36096, by the Comunidad de Madrid (Spain) (Grant S2011/BMD-2460) and by Fundación Marcelino Botín.

\section{References}

[1] Altman GH, Díaz F, Jakuba C, Calabro T, Horan RL, Chen J, et al. Silkbased biomaterials. Biomaterials 2003;24:401-16.

[2] Hu Y, Zhang Q, You R, Wang L, Li M. The relationship between secondary structure and biodegradation behavior of silk fibroin Scaffolds. Adv Mater Sci Eng 2012:185905.

[3] Kundu B, Rajkhowa R, Kundu SC, Wang X. Silk fibroin biomaterials for tissue regenerations. Adv Drug Del Rev 2013;65:457-70.

[4] Gertz CC, Leach MK, Birrell LK, Martin DC, Feldman EL, Corey JM. Accelerated neuritogenesis and maturation of primary spinal motor neurons in response to nanofibers. Dev Neurobiol 2010;70:589-603.

[5] Tysseling-Mattiace VM, Sahni V, Niece KL, Birch D, Czeisler C, Fehlings MG, et al. Self-assembling nanofibers inhibit glial scar formation and promote axon elongation after spinal cord injury. J Neurosci 2008;28:3814-23.

[6] Leung V, Ko F. Biomedical applications of nanofibers. Polymers Adv Tech 2011:22:350-65.

[7] Nirmala R, Nam KT, Navamathavan R, Park SJ, Kim HY. Hydroxyapatite mineralization on the calcium chloride blended polyurethane nanofiber via biomimetic method. Nanoscale Res Lett $2011 ; 6: 2$. 
[8] Yoshimoto H, Shin YM, Terai H, Vacanti JP. A biodegradable nanofiber scaffold by electrospinning and its potential for bone tissue engineering. Biomaterials 2003;24:2077-82.

[9] McManus MC, Boland ED, Simpson DG, Barnes CP, Bowlin GL. Electrospun fibrinogen: feasibility as a tissue engineering scaffold in a rat cell culture model. J Biomed Mater Res 2007;81A:299-309.

[10] Sukigara S, Gandhi M, Ayutsede J, Micklus M, Ko F. Regeneration of Bombyx mori silk by electrospinning - Part 1: processing parameters and geometric properties. Polymer 2003;44:5721-7.

[11] Sun K, Li ZH. Preparations, properties and applications of chitosan based nanofibers fabricated by electrospinning. Express Polym Lett 2011;5:342-61.

[12] Um IC, Fang D, Hsiao BS, Okamoto A, Chu B. Electro-spinning and electro-blowing of hyaluronic acid. Biomacromolecules 2004; $5: 1428-36$

[13] Zhong S, Teo WE, Zhu X, Beuerman RW, Ramakrishna S, Yung LY. An aligned nanofibrous collagen scaffold by electrospinning and its effects on in vitro fibroblast culture. J Biomed Mater Res 2006;79A:456-63.

[14] Giller CB, Chase DB, Rabolt JF, Snively CM. Effect of solvent evaporation rate on the crystalline state of electrospun nylon. Polymer 2010;51:4225-30.

[15] Li WJ, Laurencin CT, Caterson EJ, Tuan RS, Ko F. Electrospun nanofibrous structure: a novel scaffold for tissue engineering. J Biomed Mater Res 2002;4:613-21.

[16] Reneker DH, Chun I. Nanometre diameter fibres of polymer, produced by electrospinning. Nanotechnology 1996;7:216-23.

[17] Son WK, Youk JH, Lee TS, Park WH. The effects of solution properties and polyelectrolyte on electrospinning of ultrafine poly(ethylene oxide) fibers. Polymer 2004;45:2959-66.

[18] Yang F, Murugan R, Wang S, Ramakrishna S. Electrospinning of nano/ micro scale poly(L-lactic acid) aligned fibers and their potential in neural tissue engineering. Biomaterials 2005;26:2603-10.

[19] Zarkoob S, Reneker DH, Eby RK, Hudson SD, Ertley D, Adams WW. Structure and morphology of electrospun silk nanofibers. Polymer 2004; $45: 3973-7$.

[20] Amiraliyan N, Nouri M, Kish MH. Effects of some electrospinning parameters on morphology of natural silk-based nanofibers. J Appl Polym Sci 2009;113:226-34.

[21] Ayutsede J, Gandhi M, Sukigara S, Micklus M, Chen H-E, Ko F. Regeneration of Bombyx mori silk by electrospinning. Part 3: characterization of electrospun nonwoven mat. Polymer 2005; 46:1625-34.

[22] Aznar-Cervantes SD, Vicente-Cervantes D, Meseguer-Olmo L, Cenis JL, Lozano-Pérez AA. Influence of the protocol used for fibroin extraction on the mechanical properties and fiber sizes of electrospun silk mats. Mater Sci Eng C 2013;33:1945-50.

[23] Cao H, Chen X, Huang L, Shao Z. Electrospinning of reconstituted silk fiber from aqueous silk fibroin solution. Mater Sci Eng C 2009;29:2270-4.

[24] Chen C, Chuanbao C, Xilan M, Yin T, Hesun Z. Preparation of nonwoven mats from all-aqueous silk fibroin solution with electrospinning method. Polymer 2006;47:6322-7.

[25] Chen J-P, Chen S-H, Lai G-J. Preparation and characterization of biomimetic silk fibroin/chitosan composite nanofibers by electrospinning for osteoblasts culture. Nanoscale Res lett 2012;7:170.

[26] Kim SH, Nam YS, Lee TS, Park W. H silk fibroin nanofiber. electrospinning, properties and structure. Polym J 2003;35:185-90.

[27] Meinel AJ, Kubowb KE, Klotzsch E, Garcia-Fuentes M, Smith ML, Vogel V, et al. Optimization strategies for electrospun silk fibroin tissue engineering scaffolds. Biomaterials 2009;30:3058-67.

[28] Min BM, Lee G, Kim SH, Nam YS, Lee TS, Park WH. Electrospinning of silk fibroin nanofibers and its effect on the adhesion and spreading of normal human keratinocytes and fibroblasts in vitro. Biomaterials 2004;25:1289-97.

[29] Min BM, Jeong L, Lee KY, Park WH. Regenerated silk fibroin nanofibers: water vapor-induced structural changes and their effects on the behavior of normal human cells. Macromol Biosci $2006 ; 6: 285-92$.

[30] Ohgo K, Zhao CH, Kobayashi M, Asakura T. Preparation of non-woven nanofibers of Bombyx mori silk, Samia cynthia ricini silk and recombinant hybrid silk with electrospinning method. Polymer $2003 ; 44: 841-6$.

[31] Zhang F, Zuo BQ Bai L. Study on the structure of SF fiber mats electrospun with HFIP and FA and cells behavior. J Mater Sci 2009;44:5682-7.

[32] Zhang F, Zuo B, Fan Z, Xie Z, Lu Q, Zhang X, et al. Mechanisms and control of silk-based electrospinning. Biomacromolecules 2012;13:798-804.
[33] Zhang X, Baughman CB, Kaplan DL. In vitro evaluation of electrospun silk fibroin scaffolds for vascular cell growth. Biomaterials 2008;29:2217-27.

[34] Zhou W, He J, Du S, Cui S, Gao W. Electrospun silk fibroin/cellulose acetate blend nanofibres: structure and properties. Iranian Polym J 2011;20:389-97.

[35] Zhu J, Zhan Y, Shao H, Hu X. Electrospinning and rheology of regenerated Bombyx mori silk fibroin aqueous solutions: the effects of $\mathrm{pH}$ and concentration. Polymer 2008;49:2880-5.

[36] Zhang X, Reagan MR, Kaplan DL. Electrospun silk biomaterial scaffolds for regenerative medicine. Adv Drug Del Rew 2009;61:988-1006.

[37] Baker SC, Atkin N, Gunning PA, Granville N, Wilson K, Wilson D, et al. Characterisation of the electrospun polystyrene scaffolds for threedimensional in vitro biological studies. Biomaterials 2006;27:3136-46.

[38] Lee CH, Shin HJ, Cho IH, Kang YM, Kim IA, Park KD, et al. Nanofiber alignment and direction of mechanical strain affect the ECM production of human ACL fibroblasts. Biomaterials 2005;26:1261-70.

[39] Baumgarten PK. Electrostatic spinning of acrylic microfibers. J Colloid Interface Sci 1971;36:71-9.

[40] Deitzel JM, Kleinmeyer J, Harris D, Beck Tan NC. The effect of processing variables on the morphology of electrospun nanofibers and textiles. Polymer 2001;42:261-72.

[41] Fong H, Reneker DH. Electrospinning and formation of nanofibers. In: Salem DR, Sussman MV, editors. Structure formation in polymeric fibers. Münich (Germany): Hanser; 2000. p. 225-46.

[42] Garg K, Bowlin GL. Electrospinning jets and nanofibrous structures. Biomicrofluidics 2011;5:13403.

[43] Ramakrishna S, Fujihara K, Teo WE, Yong T, Ma A, Ramaseshaa R. Electrospun nanofibers: solving global issues. Mater Today 2006;9:40-50.

[44] Li Z, Wang C. In: Effects of working parameters on electrospinning in one-dimensional nanostructures: electrospinning technique and unique nanofibers. SpringerBriefs in materials. Berlin Heidelberg (Germany): Springer; 2013. p. 15-28.

[45] Schneider CA, Rasband WS, Eliceiri KW. NIH Image to Imagej: 25 years of image analysis. Nat Methods 2012;9:671-5.

[46] Hu B-W, Zhou P, Noda I, Ruan Q-X. Generalized two-dimensional correlation analysis of NMR and Raman spectra for structural evolution characterizations of silk fibroin. J Phys Chem B 2006; 110:18046-51.

[47] Pérez-Rigueiro J, Viney C, Llorca J, Elices M. Silkworm silk as an engineering material. J Appl Polym Sci 1998;70:2439-47.

[48] Guinea GV, Pérez-Rigueiro J, Plaza GR, Elices M. Volume constancy during stretching of spider silk. Biomacromolecules 2006;7:2173-7.

[49] Sukigara S, Gandhi M, Ayutsede J, Micklus M, Ko F. Regeneration of Bombyx mori silk by electrospinning. Part 2. process optimization and empirical modeling using response surface methodology. Polymer 2004;45:3701-8.

[50] Zong XH, Kim K, Fang DF, Ran SF, Hsiao BS, Chu B. Structure and process relationship of electrospun bioabsorbable nanofiber membranes. Polymer 2002;43:4403-12.

[51] Bailey, AG. In Electrostatic spraying of liquids, New York: Wiley, Research Studies Press, LTD Taunton, Somerset/John Wiley \& Sons; 1988.

[52] Um IC, Kweon H, Lee KG, Park YH. The role of formic acid in solution stability and crystallization of silk protein polymer. Int J Biol Macromol 2003;33:203-13.

[53] Wei W, Zhang YP, Zhao YM, Luo J, Shao HL, Hu XC. Bio-inspired capillary dry spinning of regenerated silk fibroin aqueous solution. Mater Sci Eng C 2011;31:1602-8.

[54] Van der Schueren L, De Schoenmaker B, Kalaoglu ÖI, De Clerck K. An alternative solvent system for the steady state electrospinning of polycaprolactone. Eur Polym J 2011;6:1256-63.

[55] Fridrikh SV, Yu JH, Brenner MP, Rutledge GC. Controlling the fiber diameter during electrospinning. Phys Rev Lett 2003;90:144502.

[56] Sashina ES, Bochek AM, Novoselov NP, Kirichenko DA. Structure and solubility of natural silk fibroin. Rus J Appl Chem 2006;79:869-76.

[57] Ando 1. Some aspects of the NMR chemical shift/structure correlation in the structural characterization of polymers and biopolymers. Polym J 2012;44:734-47.

[58] Mielke SP, Krishnan VV. Characterization of protein secondary structure from NMR chemical shifts. Prog Nucl Mag Res Sp 2009;54:141-65.

[59] Robustelli P, Cavalli A, Vendruscolo M. Determination of protein structures in the solid state from NMR chemical shifts. Structure $2008 ; 16: 1764-9$. 
[60] McDermott AE. Structural and dynamic studies of proteins by solidstate NMR spectroscopy: rapid movement forward. Curr Opin Struct Biol 2004; 14:554-61.

[61] Castellani F, van Rossum B, Diehl A, Schubert M, Rehbein K, Oschkinat $\mathrm{H}$. Structure of a protein determined by solid-state magic-angle-spinning NMR spectroscopy. Nature 2002;420:98-102.

[62] Li Y, Berthold DA, Gennis RB, Rienstra CM. Chemical shift assignment of the transmembrane helices of DsbB, a 20-kDa integral membrane enzyme, by 3D magic-angle spinning NMR spectroscopy. Protein Sci 2008;17:199-204.

[63] Zhou DH, Shea JJ, Nieuwkoop AJ, Franks WT, Wylie B], Mullen C, et al, Solid-state protein-structure determination with proton-detected triple-resonance 3D magic-angle-spinning NMR spectroscopy. Angew Chem Int Ed Engl 2007;46:2714-26.

[64] Asakura T, Ashida J, Yamane T, Kameda Y, Nakazawa K, Ohgo K, et al. A repeated $\beta$-turn structure in poly(Ala-Gly) as a model for Silk $I$ of Bombyx mori silk fibroin studied by two-dimensional spin-diffusion NMR under off magic angle spinning and rotational echo double resonance. J Mol Biol 2001;306:291-305.

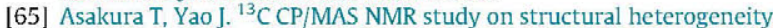
in Bombyx mori silk fiber and their generation by stretching. Protein Sci 2002;11:2706-13.

[66] Asakura T, Suzuki Y, Nakazawa Y, Yazawa K, Holland GP, Yarger JL. Silk structure studied with nuclear magnetic resonance. Prog Nucl Mag Res Sp 2013;69:23-68.

[67] Nagano A, Kikuchi Y, Sato H, Nakazawa Y, Asakura T. Structural characterization of silk-based water-soluble peptides (Glu)n(Ala-LySer-Gly-Ala-Gly)4 $(n=4-8)$ as a mimic of Bombyx mori silk fibroin by 13C solid-state NMR. Macromolecules 2009;42:8950-8.

[68] Yao J, Ohgo K, Sugino R, Kishore R, Asakura T. Structural analysis of Bombyx mori silk fibroin peptides with formic acid treatment using high-resolution solid-state ${ }^{13} \mathrm{C}$ NMR spectroscopy. Biomacromolecules 2004;5:1763-9.
[69] Dang Q Lu S, Yu S, Sun P, Yuan Z. Silk fibroin/montmorillonite nanocomposites: effect of $\mathrm{pH}$ on the conformational transition and clay dispersion. Biomacromolecules 2010;11:1796-801.

[70] Zhou P, Li G, Shao Z, Pan X, Yu T. Structure of Bombyx mori silk fibroin based on the DFT chemical shift calculation. J Phys Chem B 2001;105:12469-76.

[71] Spera S, Bax A. Empirical correlation between protein backbone conformation and $C \alpha$ and $C \beta{ }^{13} \mathrm{C}$ nuclear magnetic resonance chemical shifts. J Am Chem Soc 1991;113:5490-2.

[72] Wishart DS, Sykes BD, Richards FM. Relationship between nuclearmagnetic-resonance chemical-shift and protein secondary structure. J Mol Biol 1991;222:311-33.

[73] Osapay K, Case DA. Analysis of proton chemical shifts in regular secondary structure of proteins. J Biomol NMR 1994;4:215-30.

[74] Wishart DS, Bigam CG, Holm A, Hodges RS, Sykes BD. ${ }^{1} \mathrm{H},{ }^{13} \mathrm{C}$ and ${ }^{15} \mathrm{~N}$ random coil NMR chemical shifts of the common amino acids. I. Investigations of nearest-neighbor effects. J Biomol NMR 1995;5:67-81.

[75] Kumari A, Dorai K. Identifying secondary structures in proteins using NMR chemical shift 3D correlation maps. J Mol Struct 2013;1041:200-12.

[76] Corsini P, Pérez-Rigueiro J, Guinea GV, Plaza GR, Elices M, Marsano E, et al. Influence of the draw ration on the tensile and fracture behavior of NMMO regenerated silk fibers. J Polym Sci B $2007 ; 45: 2568-79$.

[77] Yan J, Zhou G, Knight DP, Shao Z, Chen X. Wet-spinning of regenerated silk fiber from aqueous silk fibroin solution: discussion of spinning parameters. Biomacromolecules 2010;11:1-5.

[78] Zhou G, Shao Z, Knight DP, Yan J, Chen X. Silk fibers extruded artificially from aqueous solutions of regenerated Bombyx mori silk fibroin are tougher than their natural counterparts. Adv Mater 2009;21:366-70. 